patients, took a detailed history of their upbringing and showed them how current maladaptive behaviours grew out of earlier forms of interaction with family and others which needed revision to become more appropriate to current circumstances. Western psychotherapists using a similar approach might have been surprised to hear that Pavlov was its progenitor. Now Ryle $\&$ Kerr see it as part of cognitive analytic therapy (CAT), which takes about 16 sessions. Together with the patient, the therapist writes a reformulation letter that sets out aims in therapy. The patient selfmonitors, with the help of a diary, to spot problems as they arise and try to revise them, and rates target problems. The patient and therapist exchange goodbye letters at the penultimate or last session to review what has been achieved or remains to be done, and follow-up is arranged.

Case examples show how CAT assessment is done and reformulation letters and diagrams are constructed. Its use of a goal-oriented approach, diary-keeping, self-ratings and collaboration with the patient overlaps with the practice of behavioural and cognitive therapists. However, a case history of CAT in a patient with obsessive-compulsive rituals (pp.138-144) highlights how CAT differs from behaviour therapy by exposure and ritual prevention: the 'target problem' procedures did not mention the rituals, the post-treatment rating of improvement did not say whether or not rituals reduced, and a mean of 16 sessions of 'brief' CAT exceeds the 9 sessions usual with face-to-face behavioural therapy, let alone the single hour of clinician contact needed with computeraided behavioural therapy. The authors acknowledge the paucity of controlled trials of CAT. The aim of CAT in early dementia seemed unclear (p. 156).

The authors say that CAT derives its ideas from evolutionary psychology, genetics, developmental neurobiology and psychology, and uses a 'Vygotskian perspective' regarding 'sign mediation', 'Bakhtinian concepts of the dialogic self' and 'Kellyian personal construct therapy, cognitive therapy and psychoanalytic object relations theory'. These supposed roots remind one of the historian's warning of 'idols of origin'.

A would-be practitioner might learn more from the book's case illustrations than its turgid theoretical digressions, replete with redundant argot. We need not have heard of Vygotsky to know about meaning, intention and signs, or of Bakhtin to know that we are social beings.

The case histories give an idea of what CAT is about, but the book testifies to the long journey ahead before psychotherapy can reach the authors' laudable goal of a lucid language, method and evidence-base shared by all practitioners.

Isaac Marks Emeritus Professor, Institute of Psychiatry, King's College London, and Senior Research Investigator and Honorary Consultant Psychiatrist, Department of Psychiatry, Faculty of Medicine, Imperial College School of Science, Technology \& Medicine, 303 North End Road, London WI4 9NS, UK

\section{Confidentiality and Mental Health}

Edited by Christopher Cordess. London: Jessica Kingsley. 2000. 192 pp. Ł16.95 (pb). ISBN I 853028606

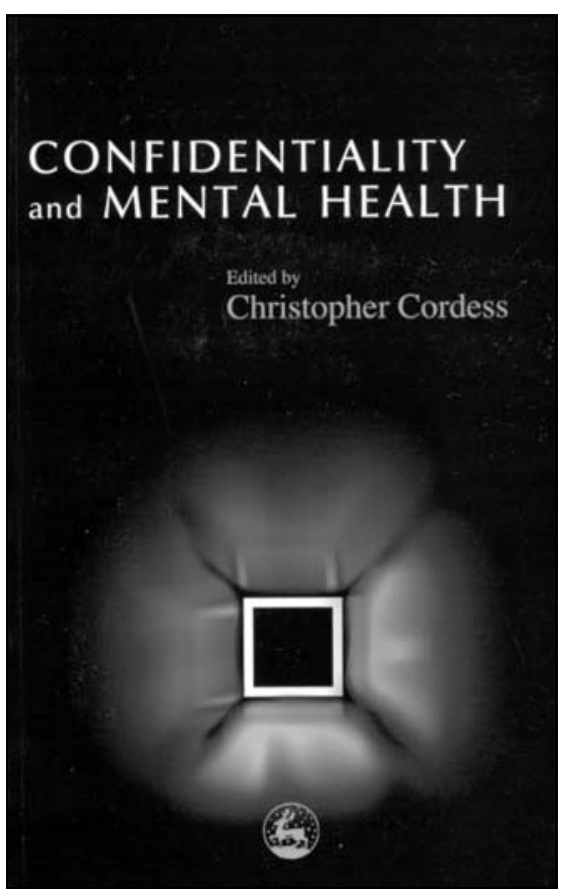

As I write this review, British soldiers are appearing anonymously behind screens in courts to discuss the Bloody Sunday shootings of 1972, and the jury reads Princess Diana's letters in silence so as not to disclose their secrets. In court, a journalist has been ordered to divulge his source of information from Ian Brady's confidential medical records. Jeffrey Archer has named inmates he encountered in prison, and has been punished for this. Confidentiality and disclosure - is always in the news.

Once upon a time, it may have been straightforward to determine the boundaries of confidentiality. That was before the GMC, BMA, MRC and Royal College of Psychiatrists issued guidelines. The report of the Caldicott Committee in 1997, the Human Rights Act 1988 and the Data Protection Act 1998 have all sought to reduce the unnecessary flow of information, but multi-agency public protection panels and the National Service Framework demand communication with others. In recent years, it has become difficult to know what a secret is - or should be. It is easy to be paralysed by uncertainty about whether to disclose information or to maintain secrecy.

This book sprang from a conference in Sheffield in 1998, and thus has the strengths and weaknesses of conference proceedings. It is inconsistent and variable in style. It will date. Nevertheless, it is far more helpful than the plethora of guidelines issued by the acronymic organisations above. Rather than laying down graven principles, this volume seeks out the interstices of understood practice. Consequently, its focus is on practical difficulties rather than ensuring that one can adhere to the law. The authors attack the subject from a number of angles and are pleasingly multi-disciplinary.

The specifics of this book are the milieux in which psychiatrists are challenged by the dilemmas of confidentiality and its mandated breach, in either private or public interest. The volume covers children, psychoanalysis, prisons and research. Approaches are variably psychodynamic, ethical, legal and clinical. The multi-author approach works well in expounding the different needs of specific populations of patients. Some chapters shine: Fulford, Szmukler \& Holloway, Bailey and Kaul are particularly provocative and helpful. In discussions about, for instance, whether to disclose confessions of paedophilia and risk the therapeutic relationship, this book is instrumental in laying bare the underlying issues. No simple guidelines could ever address the complexity of such issues.

It is unreasonable to expect that any single volume will provide a do-it-yourself guide sufficient to manage the subtle and varied situations that delineate the tension between privacy and disclosure. However, a strong approach would seek to define the 
terrain in which the problem is set and then develop themes that explain why some approaches are justified and others are not. This volume succeeds in these tasks, not just as an academic text but as a practical help. I recommend it highly.

Danny Sullivan Staff Grade Psychiatrist, HM Prison Belmarsh, London SE28 OEB, UK

\section{Sex Differences in Antisocial Behaviour. Conduct Disorder, Delinquency and Violence in the Dunedin Longitudinal Study}

ByTerrie E. Moffitt, Avshalom Caspi, Michael Rutter \& Phil A. Silva. Cambridge: Cambridge University Press. 2001.278 pp. $€ 40.00$ (hb). ISBN 0521010667

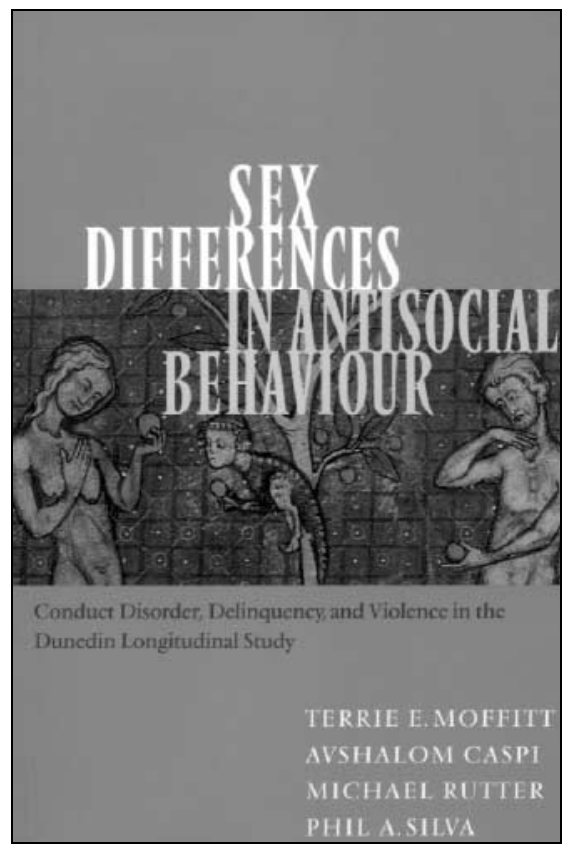

About the most robust finding in the area of antisocial behaviour is that it is more common in males than in females. This book examines this gender difference in detail and considers its implications for understanding the underlying causes of antisocial behaviour. It presents findings from the Dunedin Longitudinal Study, which followed a cohort of 1000 New Zealand males and females over the first two decades of life. The findings are presented in a clear, well-organised way, with useful discussion and bullet-point 'take-home messages' at the end of each chapter.

The study finds no difference in the causes of antisocial behaviour between the genders and no evidence to support the hypothesis that females must pass a higher threshold of risk to develop a disorder. The genders differ most on the more serious lifecourse-persistent pattern of antisocial behaviour. This pattern is rare in women, with a ratio of 10 men to one woman in the study cohort. The majority of females who engage in antisocial behaviour fit the adolescence-limited pattern and the gender ratio here is much lower (1.5 males to 1 female). Individual neurodevelopmental factors - specifically, neurocognitive deficits, undercontrolled temperament, weak constraint and hyperactivity - are identified as key to understanding life-coursepersistent antisocial behaviour. The fact that these neurodevelopmental risk factors occur more frequently in males is used to explain the male preponderance of this pattern of antisocial behaviour.

Three exceptions to the general rule that antisocial behaviour is more common in males than in females are identified: (a) around the time of female puberty, the incidence and prevalence of female conduct disorder rises to give the narrowest gap between the genders seen at any stage in the life cycle; (b) males and females are similar in their drug- and alcohol-related offences; and (c) in intimate relationships, where male violence is at least equalled by female violence.

The authors identify two priority areas for future research. First, we need to know more about the neurodevelopmental problems, their origins, why they are more common in males and how they interrelate and influence development over time, in order to develop a greater understanding of life-course-persistent antisocial behaviour. The interesting question is raised of whether this pattern ought to be viewed as a developmental neuropsychiatric disorder. Second, we need research into how the specific social contexts of puberty that are associated with substance misuse and intimate relationships promote similarity in antisocial behaviour between the genders. This would be more revealing than the continuing focus on how gender-stereotyped socialisation promotes differences between males and females.

This book presents complex research findings in a stimulating, accessible style.
Its findings, particularly in relation to the importance of neurodevelopmental difficulties, are of direct relevance to both clinicians and researchers.

Mary Naughton Consultant Child and

Adolescent Psychiatrist, Child and Family Service, Adcote House, Kent Street, Off Alton Road, Oxton, Birkenhead CH43 6TX, UK

\section{Weathering the Storms. Psychotherapy for Psychosis}

By Murray Jackson. London: Karnac Books. 200I. 392 pp. $€ 29.99$ (pb). ISBN I 855752670

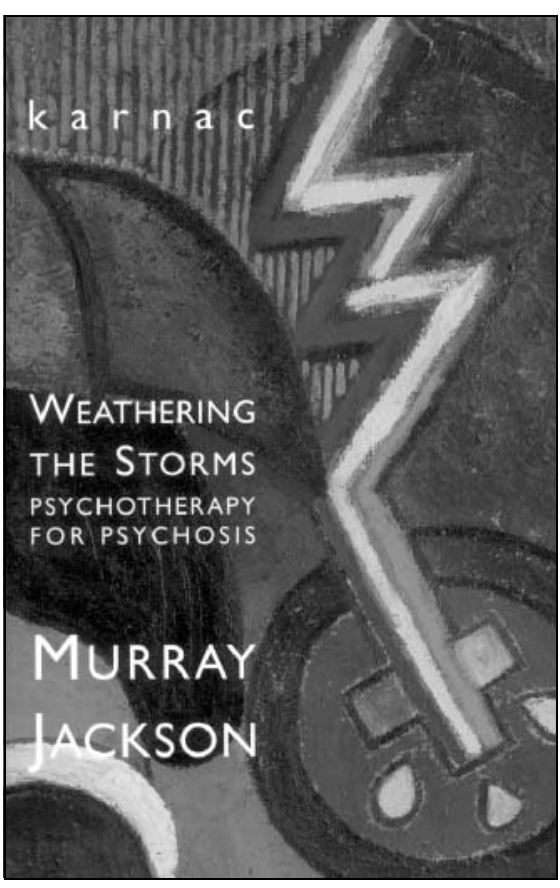

Books and theorists on schizophrenia are numerous; however, this title stands out, as having a significantly different story to tell. Psychiatric approaches to psychosis, built on biological determinism, are often criticised for their neglect of meaning, purpose and individuality - here is a counterweight full of all these elements. This is a timely, impressive and provocative book.

Timely, because it is devoted to the meaning of psychotic experience and the process of sustaining committed therapeutic relationships, and is thus in allegiance with the growing emphasis on recovery.

Impressive, because Jackson has spent a professional lifetime bridging the gap 